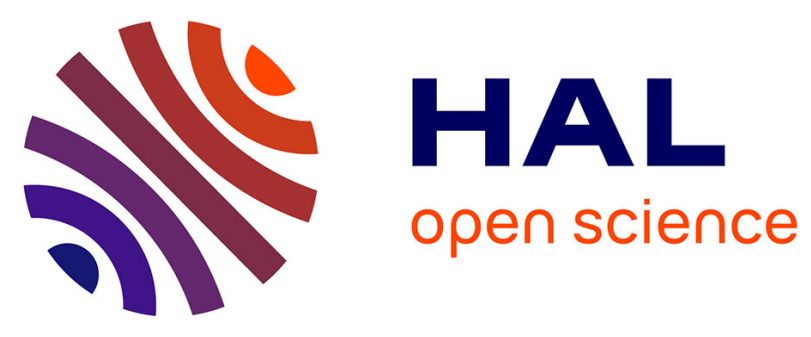

\title{
Memristor Device Characterization by Scanning Microwave Microscopy
}

Gilbert Sassine, N. Najjari, Charlene Brillard, N. Defrance, Olaf C Haenssler, Didier Theron, F. Alibart, Kamel Haddadi

\section{- To cite this version:}

Gilbert Sassine, N. Najjari, Charlene Brillard, N. Defrance, Olaf C Haenssler, et al.. Memristor Device Characterization by Scanning Microwave Microscopy. International Conference on Manipulation, Automation and Robotics at Small Scales (MARSS), Jul 2017, Montréal, Canada. 10.1109/MARSS.2017.8016537 . hal-02311382v2

\section{HAL Id: hal-02311382 \\ https://hal.science/hal-02311382v2}

Submitted on 14 Oct 2019

HAL is a multi-disciplinary open access archive for the deposit and dissemination of scientific research documents, whether they are published or not. The documents may come from teaching and research institutions in France or abroad, or from public or private research centers.
L'archive ouverte pluridisciplinaire HAL, est destinée au dépôt et à la diffusion de documents scientifiques de niveau recherche, publiés ou non, émanant des établissements d'enseignement et de recherche français ou étrangers, des laboratoires publics ou privés. 


\title{
Memristor Device Characterization by Scanning Microwave Microscopy
}

\author{
${ }^{1}$ G. Sassine, ${ }^{1}$ N. Najjari, ${ }^{1}$ C. Brillard, ${ }^{1}$ N. Defrance, ${ }^{1,2}$ O. C. Haenssler, ${ }^{1}$ D. Theron, ${ }^{1}$ F. Alibart and ${ }^{1}$ K. Haddadi \\ ${ }^{1}$ Institute of Electronics, Microelectronics and Nanotechnology (IEMN), University of Lille, CNRS, UMR 8520 \\ Avenue Poincaré CS 60069 - 59652 Villeneuve d'Ascq Cedex - France \\ ${ }^{2}$ Department for Computing Science, University of Oldenburg, 26129 Oldenburg, Germany. \\ kamel.haddadi@iemn.univ-lille1.fr
}

\begin{abstract}
We report memristive device characterization using near-field scanning microwave microscopy. Atomic force microscopy, magnitude and phase-shift images of the complex reflection coefficient of $\mathrm{TiO}_{2}$ devices can be acquired simultaneously in the range 1-20 GHz. In particular, measurement of the complex reflection coefficient of a 200 by $200 \mathrm{~nm}^{2} \mathrm{TiO}_{2}$ device is exemplary demonstrated. These results are beneficial for electrical modeling and optimization of memristor devices to address OxRAM applications.
\end{abstract}

Keywords - Oxide based random access memory (OxRAM), memristor, scanning microwave microscopy, atomic force microscopy, interferometry, metal oxide semiconductor capacitors.

\section{INTRODUCTION}

Resistive random access memory (RRAM) technologies have experienced an increasing interest these last years as a promising solution for storage and memory [1]. Indeed, emerging memory devices can offer potential alternative for flash technology or DRAM, thanks to their fast switching performances, high retention and cycling endurance, scalability, and back-end-of-line integration potential. Global understanding of the relative contribution of the different physical mechanisms is very challenging and significant efforts at the modeling and material characterization levels are still needed [2].

In this paper, we propose an analysis in the microwave domain to study dynamics in nanometer memristive devices. In particular, we consider $\mathrm{TiO}_{2}$ material that has been largely investigated as prototypical material system for switching. A broadband near-field scanning microwave microscope (NSMM) consisting of an atomic force microscope combined with a vector network analyzer (VNA) is used to study the memristive devices [3]. Basically, the tip scans across the sample, emitting a microwave signal scattered by the material, altering its amplitude or/and phase properties [4-9]. The measurement setup and device fabrication including dedicated calibration kit are described in Section II. Preliminary experimental results are presented in Section III. In particular, microwave response of the memristive device as a function of the applied bias is demonstrated around $18 \mathrm{GHz}$.

\section{MATERIAL AND METHODS}

\section{A. Interferometric SMM setup}

The interferometric set-up of the NSMM is depicted in Fig. 1. It consists of a Keysight ${ }^{\mathrm{TM}} \mathrm{LS} 5600$ AFM interfaced with a Keysight $^{\mathrm{TM}}$ PNA series network analyzer E8362B through a homemade tuned interferometric matching network based on the Mach-Zehnder method [10-11]. This latter is built up in coaxial form with a power divider, two hybrid couplers, an active variable attenuator and two amplifiers in series. The basic principle consists in splitting the PNA source high frequency power wave $a_{1}$ in two coherent signals, i.e. the reference signal $a_{\mathrm{INC}}$ to the AFM tip and the interference signal. The coupler associated to the AFM tip acts as a reflectometer to separate the incident wave $a_{\mathrm{INC}}$ and the reflected wave $a_{\text {REF }}$ from the device under test (DUT). The wave $a_{\mathrm{REF}}$ is then combined with the interference signal to provide the output signal $a_{3}$ at the output of the second coupler. This signal $a_{3}$ is cancelled by properly tuning the attenuator to balance the magnitudes of $a_{\text {REF }}$ and the interference signal. The resulting signal $a_{3}$ signal is amplified and measured by the PNA receiver.

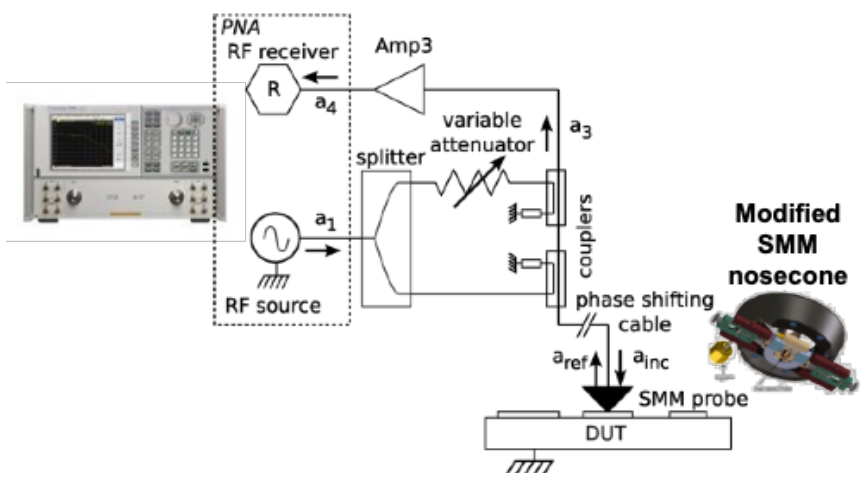

Fig. 1. Set-up of the scanning microwave microscope incorporating a tuned interferometric matching network based on the Mach-Zehnder method. 
The resulting measured reflection coefficient $\Gamma=a_{4} / a_{1}$ considering ideal components can be expressed as a function of the reflection coefficient $\Gamma_{\mathrm{DUT}}=a_{R E F} / a_{I N C}$ of the DUT by:

$$
\Gamma=\alpha\left(\Gamma_{\mathrm{DUT}}+\beta\right)
$$

where $\alpha$ is a complex coefficient taken into account losses and phase-shifts introduced by the microwave circuitry and $\beta$ denotes the interference signal. At the test frequency and for a DUT with reference impedance $Z_{\text {REF, the magnitude of the }}$ reflection coefficient $\Gamma$ is set to zero resulting in high measurement sensitivity for impedances around $Z_{\text {REFF }}$.

\section{B. OxRAM devices and calibration kit fabrication}

$\mathrm{TiO}_{2}$ devices were realized on a P-type silicon substrate of resistivity $1-3 \Omega \mathrm{cm}$ (Fig. 2). The devices consist of $\mathrm{Ti}$ $(5 \mathrm{~nm}) / \mathrm{Pt}(30 \mathrm{~nm}) / \mathrm{TiO}_{2-\mathrm{x}} / \mathrm{TiO}_{2} / \mathrm{Pt}(15 \mathrm{~nm}) / \mathrm{Au}(20 \mathrm{~nm})$ from bottom to top. All metals were deposited by e-beam evaporation, and top electrodes were patterned by electron beam lithography (EBL) with targeted dimensions between $200 \times 200$ and $60 \times 60 \mathrm{~nm}^{2}$. $\mathrm{TiO}_{2-x} / \mathrm{TiO}_{2}$ films were obtained by atomic layer deposition (ALD) at $200^{\circ} \mathrm{C}$ with $\mathrm{TiCl}_{4}$ as $\mathrm{Ti}$ precursor and $\mathrm{H}_{2} \mathrm{O}$ as oxygen source. The water pulses were set shorter than the ones needed to saturate the surface in order to produce an oxygen deficient $\mathrm{TiO}_{2-x}$ layer. Post-deposition oxidation of the $\mathrm{TiO}_{2-x}$ top interface into $\mathrm{TiO}_{2}$ was obtained by natural air exposure.

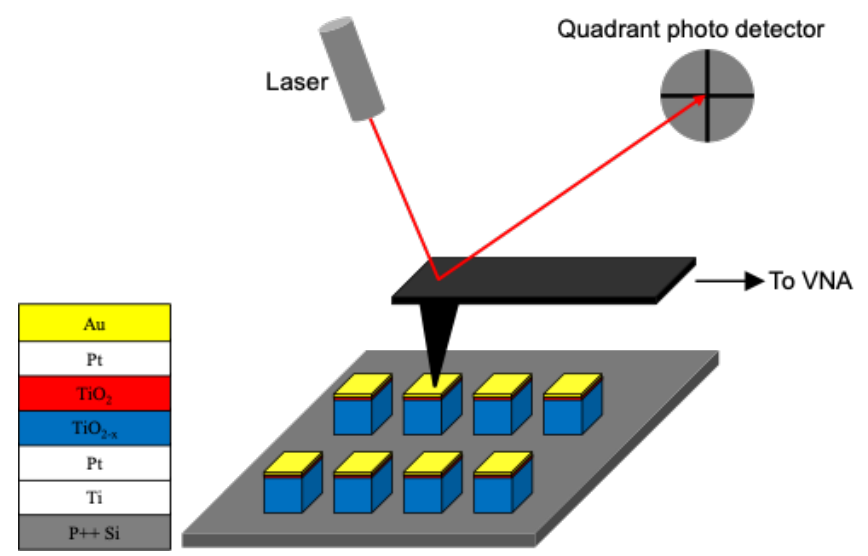

Fig. 2. Configuration of $\mathrm{TiO}_{2}$ devices under the AFM probe.

An on-wafer calibration kit consisting of MOS capacitors was fabricated on the same wafer. The MOS capacitors are composed of circular gold electrodes evaporated on $\mathrm{SiO}_{2}$ deposited on one part of the wafer (Fig. 3). In order to vary the capacitances values, the diameter of the upper gold pad varies from 0.5 to $2 \mu \mathrm{m}$ whereas the $\mathrm{SiO}_{2}$ thickness was set to $140 \mathrm{~nm}$.

From the AFM image, the topography of the $\mathrm{TiO}_{2}$ devices are extracted along the wafer (Fig. 4). The data indicate a good homogeneity of the fabrication process.

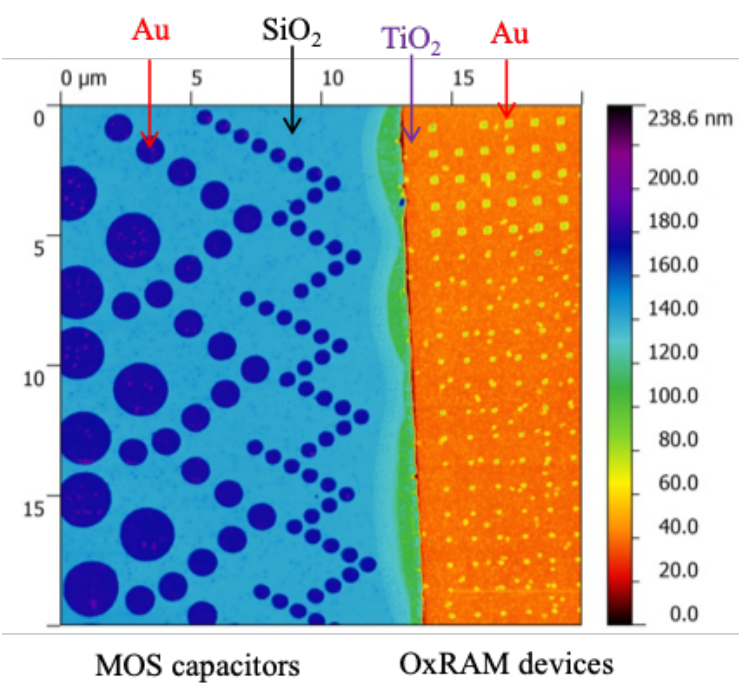

Fig. 3. AFM topography image of the fabricated sample. On the left, MOS capacitor top electrodes are measured. On the right, the OxRAM stacks are measured.

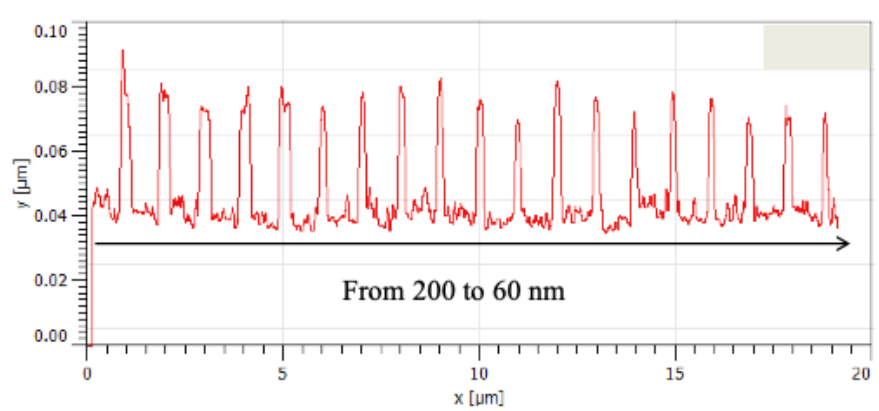

Fig. 4. 1D topography cross section of the fabricated $\mathrm{TiO}_{2}$ devices from top to bottom of the Fig. 2 image. The size of the OxRAM devices vary from $200 \times 200$ down to $60 \times 60 \mathrm{~nm}^{2}$.

The impedance of the MOS structures measured at the tip apex of the probe is modeled by a series model consisting of an oxide capacitance $C_{\mathrm{ox}}$ and a depletion capacitance $C_{\mathrm{depl}}$. Both capacitances can be described by the parallel plate capacitor formalism. The resulting capacitance $C_{\mathrm{TOT}}$ is given by

$$
C_{\mathrm{TOT}}=C_{\mathrm{ox}} C_{\mathrm{depl}} /\left(C_{\mathrm{ox}}+C_{\mathrm{depl}}\right)
$$

The parallel-plate capacitance term $C_{\mathrm{ox}}$ without taking into account the fringing fields is calculated from the area $A$ of the gold pads and the $\mathrm{SiO}_{2}$ thickness $d_{\mathrm{ox}}$ :

$$
C_{o x}=A \frac{\varepsilon_{0} \varepsilon_{r S i 0_{2}}}{d_{o x}} .
$$

The silicon dioxide is assumed to have a relative dielectric constant of $\varepsilon_{\mathrm{rSiO}_{2}}=3.9$. The thickness and areas of the capacitors were estimated from the AFM topography measurements (Fig. 3) to take into account any deviation in geometry induced by the fabrication process of the calibration kit. The measured areas $A$ were $1.13 \mu \mathrm{m}^{2}, 3.94 \mu \mathrm{m}^{2}$ and $13.85 \mu \mathrm{m}^{2}$. The charge 
stored on the capacitor is distributed across a certain depth that adds the depletion series capacitance $C_{\text {depl }}$ in series to $C_{\text {ox }}$. The capacitance was estimated to be proportional to the area $A$ of the metallic electrode and inversely proportional to the depleted zone depth $d_{\mathrm{depl}}$ according to

$$
C_{\text {depl }}=A \frac{\varepsilon_{0} \varepsilon_{r S i}}{d_{\text {depl }}}
$$

with $d_{d e p l}=\sqrt{2 \varepsilon_{0} \varepsilon_{r S i} \Psi / q N_{A}}$ and $\varepsilon_{r S i}=12$ is the relative permittivity of the silicon bulk substrate, $\Psi$ represents the energy band bending at the $\mathrm{Si} / \mathrm{SiO}_{2}$ interface and is set to 200 $\mathrm{mV}, q$ is the elementary electron charge $\left(1.6 \times 10^{-19} \mathrm{C}\right), N_{A}$ is the doping level of the silicon bulk around $8 \times 10^{15} \mathrm{~cm}^{-3}$. From relations (2) to (4), theoretical capacitance data can be derived.

\section{EXPERIMENTAL RESULTS}

The measurements were performed in contact mode around $18 \mathrm{GHz}$ using a 25PT300A AFM tip from Rocky Mountain Nanotechnology ${ }^{\mathrm{TM}}$. The RF power source is set to $-30 \mathrm{dBm}$ and the intermediate frequency bandwidth (IFBW) of the VNA is $100 \mathrm{~Hz}$. The images were scanned over a $20 \times 20 \mu \mathrm{m}^{2}$ with 2048 pixels. In addition to the topography image, the NSMM provides both magnitude and phase-shift images of $\Gamma$. Fig. 5 shows the image of the magnitude of the reflection coefficient obtained under zero-bias conditions at $\mathrm{f} \sim 17.89 \mathrm{GHz}$.

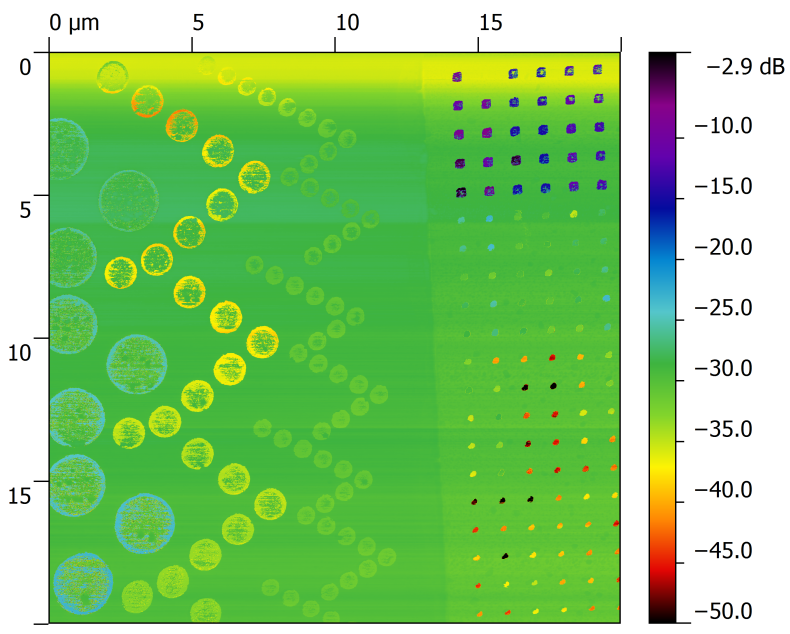

Fig. 5. Image of the magnitude of the reflection coefficient $\Gamma$ at f $\sim 17.89 \mathrm{GHz}$.

The measurement reliability is influenced by the quality of the electrical contact between tip and sample especially for capacitance gold pads. We observe on some pixels a loss of the contact between the probe and the sample during the scanning. The loss of electrical contact is most likely caused by transient contamination of the gold pads. $200 \times 200 \mathrm{~nm}^{2}$ OxRam devices (upper right of the image) are measured with high sensitivity. Magnitude contrast in respect with the background is between 18 and $24 \mathrm{~dB}$. Smallest devices are also very sensitive to the microwave signal but exhibit different responses for devices of same size. A similar phenomenon is observed for the phaseshift of $\Gamma$.
Fig. 6 shows the variation of the magnitude and phase of $\Gamma$ as a function of the DC bias applied between probe tip and the bottom of a $200 \times 200 \mathrm{~nm}^{2}$ device.

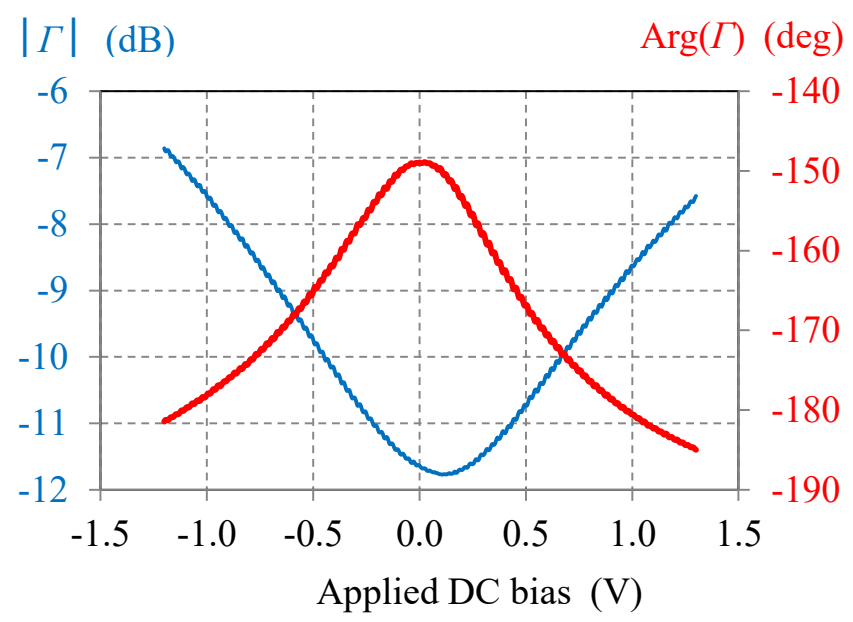

Fig. 6. Measured magnitude and phase of $\Gamma$ as a function of the DC bias at $\mathrm{f} \sim 17.89 \mathrm{GHz}$.

From these data, variations of respectively $5 \mathrm{~dB}$ and 30 degrees are observed on the measured data when the DC bias is changed from -1.2 to $1.2 \mathrm{~V}$. This is related to the dependence of the device impedance under DC bias.

\section{CONCLUSION}

Near-field scanning microwave microscopy measurement of memristive devices have been experimentally demonstrated around $18 \mathrm{GHz}$. In particular, DC bias voltage impacts both magnitude and phase-shift responses of the microwave reflection coefficient in a sensitive manner. These preliminary results are instructive for further electrical modeling of the device. In particular, future works will include full vector calibration of the devices in a broad frequency range.

\section{ACKNOWLEDGMENT}

This work is supported by the French National Research Agency (ANR) and German Research Foundation (DFG) project VACSMM. This work used the support of the RENATECH-IEMN for device fabrication. This work used the facilities within the EQPX ExCELSiOR.

\section{REFERENCES}

[1] A. C. Torrezan, J. P. Strachan, G. Medeiros-Ribeiro and R. S. williams; "Sub-nanosecond switching of a tantalum oxide memristor", Nanotechnology", vol. 22, no 48, p. 485203, 2001.

[2] G. Sassine, S. La Barbera, N. Najjari, M. Minvielle, C. Dubourdieu and F. Alibart, "Interfacial versus filamentary resistive switching in $\mathrm{TiO}_{2}$ and $\mathrm{HfO}_{2}$ devices", J. of Vacuum Science \& Technology B, Nanotechnology and Microelectronics: Materials, Processing, Measurement, and Phenomena, vol. 34, no 1, p. 012202, 2016.

[3] S. M. Anlage, V. V. Talanov, and A. R. Schwartz, "Principles of nearfield microwave microscopy," Scanning Probe Microscopy: Electrical and Electromechanical Phenomena at the Nanoscale, S. Kalinin and A. Gruverman, Eds. New York, Springer Sci., pp. 215-253, Aug. 2007. 
[4] S. Fabiani, D. Mencarelli, A. Di Donato, T. Monti, G. Venanzoni, A Morini, T. Rozzi, and M. Farina, "Broadband Scanning Microwave Microscopy investigation of graphene", Proc. IEEE MTT-S International Microw. Symp., pp. 1-4, June 2011.

[5] G. Gramse, M. Kasper, L. Fumagalli, G. Gomila, P. Hinterdorfer and F. Kienberger, "Calibrated complex impedance and permitivity measurements with SMM," Nanotechnology, vol. 25, no. 14, p. 8, 2014.

[6] Agilent Technologies, Inc., "Scanning Microwave Microscopy (SMM) Mode", Datasheet, 2013.

[7] Oxford Instruments, Inc., "Scanning Microwave Impedance Microscopy (sMIM)", Datasheet, 2014.

[8] A. Imtiaz, T. M. Wallis and P. Kabos, "Near-Field Scanning Microwave Microscopy: An Emerging Research Tool for Nanoscale Metrology", IEEE Microwave Magazine, vol.15, no.1, pp.52-64, Jan. 2014.
[9] K. Haddadi, D. Glay and Tuami Lasri, A $60 \mathrm{GHz}$ scanning near-field microscope with high spatial resolution sub-surface imaging, IEEE Microw. Wirel. Compon. Lett., 21, no. 11, pp. 625-627, 2011.

[10] T. Dargent, K. Haddadi, T. Lasri, N. Clément, D. Ducatteau, B. Legrand, H. Tanbakuchi, and D. Théron, "An interferometric scanning microwave microscope and calibration method for sub-fF microwave measurements", Rev. Sci. Instrum., vol. 84, no.12, pp. 123705-123705-7, Dec. 2013.

[11] H. Happy, K. Haddadi, D. Théron, T. Lasri and G. Dambrine, "Measurement techniques for RF nanoelectronic devices : new equipment to overcome the problems of impedance and scale mismatch", IEEE Microwave Magazine, vol. 15, no. 1, pp. 30-39. Jan. 2014. 